\title{
Analisis Penggunaan Batu Split Long Ikis Terhadap Karakteristik Campuran AC-WC (Asphal Choncrete-Wearing Course)
}

\author{
${ }^{1}$ Andi Marini Indriani, ${ }^{2}$ Agus Sugianto, ${ }^{3}$ Faisal \\ ${ }^{1,2}$ DosenProgram StudiFakultasTeknikSipildanPerencanaanUniversitas Balikpapan \\ Email :marini_sabrina@yahoo.com.sg \\ Email:agus.fadhil@yahoo.co.id \\ ${ }^{3,}$ MahasiswaFakultasTeknikSipildanPerencanaanUniversitas Balikpapan
}

\begin{abstract}
The performance of a mixed depends on a kinds and the quality of the materials in used.the agregated from the source or quarry in the different Performance of the mixtured will produce different too. the purpose of this research was fof to determine of the natural and caracterictics mixed $A C$ wearing course if used stone split Long Ikis withsubtlegradations, that isdevotedto thenature ofstability and caracterictics or parameter of examination in the marshall.The presentation result of examination in agregate shows thevaluethat meets the specifications theabrasiontest results at 21,12\% > 40\%, The averagespecific gravity at $>2,5 \%$ and the averageabsorption at $>3$. of alltest resultsmarshall whichhas beenimplementedonly partiallymeet the requirements ofthe specification.It was important tonotethe value ofstability, flow, MarshallQuotient $(M Q)$ fromThe third group of test objects can only value in the value flow partially ineligible Specifications Highways 2010 while the value ofstabilityandMarshallQuotient(MQ) meets specifications. The stabilityvaluewas1396Kgonasphalt contentat 6.0\%. and the value in marshall quotient $(M Q)$ the largestwas665Kg/mmat5.0\%binder content. In theFlowqualifiedvaluespecification >3contained in theasphalt contentof $5.5 \%, 6.0 \%, 6.5 \%$ and $7.0 \%$. While theresultsdidn't meetsthe specifications ofbitumen contentof 4.5\%and 5.0\%.Marshallparametersofthe test resultsonbitumen contentplan $(\mathrm{Pb})$ obtainedthe value ofOptimumAsphaltContent $(\mathrm{KAO})$ at $5.83 \% 6.0 \%$ rounded. For theMarshallimmersionParameter at30minutesand 24 hoursimmersionat $60{ }^{\circ}$ Cstabilityvalues obtained1326kg and $1478 \mathrm{~kg}$, flow of $3.10 \mathrm{mmand} 3.70 \mathrm{~mm}, \mathrm{VMA} 17.3 \%$ and17.4\%, VIM5.5\% and $4.5 \%, \mathrm{VFA} 68.1 \%$ and $74.8 \%$ and $431 \mathrm{kgMQ} / \mathrm{mmand} 399 \mathrm{~kg} / \mathrm{mm}$. has qualifiedspecifications.
\end{abstract}

Keywords: SplitStone, LongIkis, AC-WC mixturecharacteristics.

\begin{abstract}
Abstrak
Performa suatu campuran tergantung pada jenis dan kualitas bahan yang digunakan. Agregat dari sumber/quarry yang berbeda akan menghasilkan performa campuran yang berbeda pula. Tujuan dari penelitian ini adalah untuk mengetahui sifat dan karakteristik campuran AC-Wearing Course jika menggunakan batu split Long Ikis dengan gradasi halus, yaitu dikhususkan pada sifat stabilitas dan karakteristik/parameter pengujian Marshall. Persentase hasil pengujian agregat menunjukkan nilai yg memenuhi spesifikasi dengan hasil uji abrasi $21,12 \%<40 \%$, berat jenis rata-rata $>2,5 \%$ dan penyerapan rata-rata $<3$. Dari seluruh hasil uji marshall yang telah di laksanakan hanya sebagian yang memenuhi persyaratan spesifikasi. Penting untuk diperhatikan nilai stabilitas, flow, MarshallQuotient(MQ) dari ketiga kelompok benda uji nilai yang di dapat hanya nilai flow sebagian yang tidak memenuhi syarat Spesifikasi Bina Marga 2010 sedangkan nilai stabilitas dan MarshallQuotient $(M Q)$ sudah memenuhi spesifikasi.Nilai stabilitas terbesar yaitu $1396 \mathrm{Kg}$ pada kadar aspal 6,0\%. Dan Nilai MarshallQuotient(MQ) terbesar yaitu $665 \mathrm{Kg} / \mathrm{mm}$ pada kadar aspal 5,0\%. Pada nilai Flow yang memenuhi syarat spesifikasi >3 terdapat pada kadar aspal 5,5\%, 6,0\%, 6,5\% dan 7,0\%. Sedangkan hasil yang tidak memenuhi spesifikasi pada kadar aspal 4,5\% dan 5,0\%.Dari hasil pengujian Parameter Marshall pada kadar aspal rencana $(\mathrm{Pb})$ didapat nilai Kadar Aspal Optimum (KAO) 5,83\% dibulatkan 6,0 \%. Untuk hasil Parameter Marshall perendaman 30 menit dan perendaman 24 jam pada suhu $60^{\circ} \mathrm{C}$ didapat nilai stabilitas $1326 \mathrm{~kg}$ dan 1478 $\mathrm{kg}$, flow 3,10 mm dan 3,70 mm, VMA 17,3\% dan 17,4\%, VIM 5,5\% dan 4,5\%, VFA 68,1\% dan 74,8\% dan MQ 431 $\mathrm{kg} / \mathrm{mm}$ dan $399 \mathrm{~kg} / \mathrm{mm}$. telah memenuhi syarat spesifikasi.
\end{abstract}

Kata Kunci :Batu Split Long Ikis, Sifat dan Karakteristik Campuran AC-WC 


\section{Pendahuluan}

Perkembangan industri konstruksi jalan semakin berkembang pesat.Perkembangan ini diikuti oleh penemuan-penemuan inovasi material/bahan.Untuk mendukung perkembangan teknologi konstruksi jalan yang semakin maju diperlukan material/bahan yang bermutu dan berkualitas tinggi, oleh karena itu perlu pengetahuan tentang jenis dan karakteristik dari material/bahankonstruksi.

Salah satu batuan yang ada di kelurahan Long Ikis adalah batu split. Batu alam lokal Kelurahan Long Ikis banyak terdapat pada bukit-bukit pegunungan daerah tersebut. Saat ini batu split ini umumnya masyarakat digunakan sebagai campuran dalam adonan cor beton, pondasi dan kontruksi bangunan lainnya. masih jarang menggunakan batu split lokal ini sebagai alternatif pilihanpertamauntuk material/ bahanpengganti dalam campuran aspal.

Batu split Long Ikis dapatdikategorikan sebagaisalahsatumacam batuan kapur, yaitumerupakanendapanyang terbentukmelaluiproseskimiaatau mekanismedalam alam(Bodja Suwanto et.al., 2002). Batu split long ikis mempunyaiciricirifisik berupa batuan yang keras, tekstur kasar, monolitdalam jumlah kubikasiyangbesardan berwarnaagak putih. Batu inimempunyaidaya penyerapan air, nilaikeausan dan nilai kekasaran yang lebih tinggi dibandingkan dengan batu belah sungai(Marsudi,2004).Berdasarkanbeberapa penelitian yang pernah dilakukan untuk kinerja properties batupecah yang berasal dari batu sungai menunjukkan nilai yang lebih baik jika dibandingkan dengan material yang berasal dari batu pecah gunung.Tapi tidak tertutup kemungkinan bahwa batu split long ikis ini bisa dijadikan material konstruksi perkerasan jalan, asal memenuhi spesifikasi yang disyaratkan, dalam penelitian ini memenuhi persyaratan spesifikasi Bina Marga 2010.

Pada saat sekarang ini, pemakaian lapisan aspal beton (Laston) sudah semakin banyak digunakan.Laston (Asphaltic Concrete,
$A C$ ) yang dibuat sebagai campuran panas (HotMix), merupakan konstruksi pendukung dari perkerasan lentur ( Fleksible Pavement ) dan merupakan konstruksi perkerasan yang paling umum digunakan.Laston memiliki tingkat fleksibelitas yang tinggi sehingga penempatan langsung di atas lapisan seperti lapisan aus (AC-Wearing Course) membuat lapisan ini rentang terhadap kerusakan akibat temperatur yang tinggi dan beban lalu lintas berat. Jenis kerusakan yang sering terjadi pada Laston adalah pelepasan butiran dan retak.

Dalam pencampuran, digunakan berbagai jenis agregat yang secara umum terdiri dari agregat kasar, agregat halus, serta filler atau bahan pengisi. Pada umumnya campuran dari masing-masing agregat yang dipakai berbedabeda untuk setiap penggunaan campuran. Sehingga dalam hal ini karakteristik dari agregat akan sangat berpengaruh terhadap sifat-sifat campuran itu sendiri. Oleh karena itu perlu dilakukan penelitian terhadap berbagai jenis agregat untuk memperoleh nilai stabilitas yang baik dan memenuhi syarat spesifikasi.

\section{Tinjauan Pustaka}

\subsection{Pengertian Batu Split}

Batu split merupakan material yang sering digunakan dalam mendirikan berbagai bangunan, pembuatan jalan dan sebagainya. Material ini terbuat dari batu besar yang kemudian dipecah menjadi ukuran yang lebih kecil. Karena itu batu split ini dikenal juga dengan sebutan batu belah. Nama ini dikaitkan dengan proses pembuatan batu ini.

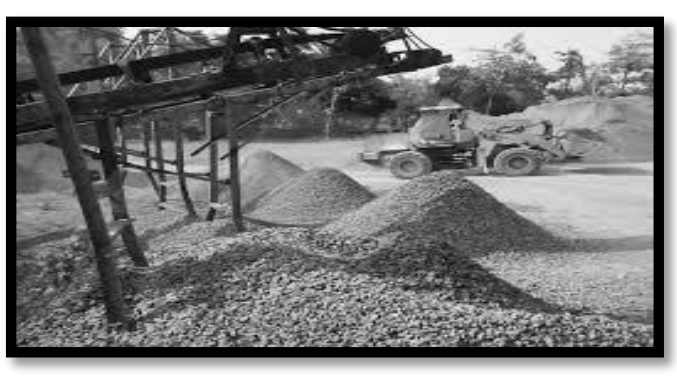

Gambar 2.1 Proses Pemecahan Batu

\subsection{Lapisan Beton Aspal}

Lapis beton aspal adalah lapisan penutup konstruksi jalan yang mempunyai nilai 
struktural yang pertama kali dikembangkan di Amerika oleh The Asphalt Institude dengan nama Asphalt Concrete (AC). Menurut Bina Marga Departemen Pekerjaan Umum, campuran ini terdiri atas agregat menerus dengan aspal keras, dicampur, dihamparkan dan dipadatkan dalam keadaan panas pada suhu tertentu.

\subsection{Agregat}

Agregatataugranularmaterial adalahmaterialberbutiryangkeras dankompak.Istilahagregatmencakupantaralainb atubulat,batupecah,abubatu, danpasir.Agregat mempunyaiperananyangsangatpentingdalam prasarana transportasi,khususnyadalamhalini padaperkerasanjalan,dimanaagregat menempati proporsi terbesardalamcampuran,umumnyaberkisar $90 \%$ $-95 \%$ dari berattotalcampuran.

\subsection{Sifat Campuran}

Bila agregat dicampurkan dengan aspal,ada beberapa kondisi umum yang akan terjadi, yaitu permukaan agregat akan diselimuti aspal diikuti dengan pori-pori agregat. Demikian pula dengan rongga diantara butiran agregat akan terisi aspal. Namun baik pori-pori agregat maupun rongga diantara agregat, tidak selalu teriasi penuh oleh aspal,ada bagian tersisa yang pasti terisi oleh udara. Adalah logis makin banyak kadar aspal makin banyak ruang dan pori yang terisi oleh aspal.

\section{Metodologi Penelitian}

\subsection{Metode Penelitian}

Pada penelitian ini,metode yang digunakan adalah metode eksperimen. Berdasarkan pedoman perencanaan campuran beraspal panas dengan metode Marshall menurut American Association of State Highway and Transportation Official (AASHTO,1998) dan Spesifikasi Umum Bidang Jalan dan Jembatan tahun 2010.

Pengujian-pengujian yang dilakukan meliputi:

1. Pengujian agregat meliputi: Berat Jenis, dan Keausan (Los Angeles Abrasion).

2. Mempersiapkan bahan,yaitu menyaring agregat untuk kebutuhan perencanaan campuran rencana (JobMixFormula).

3. Membuat benda uji Marshall.

Pengujian benda uji Marshall dengan tujuan mendapatkan sifat-sifat seperti: Stabilitas, Flow, VIM(VoidInTheMix),VFA(Void Filled With Asphalt), VMA(Void Mix Aggregate) dan Marshall Quotient (MQ).

\section{Metode Pengumpulan Data}

Metodepengumpulandataprimerdilakukan dengancarapencatatanlangsung darihasilpengujian

yangakandilakukanterhadapsampelpercobaand ilaboratoriumsesuai dengan prosedur MarshallTest.

\subsection{Persiapan Bahan}

Bahanyangdigunakanuntukpengujianadalah:

1. Agregatyangdipakaiadalah hasil pemecahan batu split,batuini diperoleh dari daerah Long Ikis.

2. Untukbahanaspalmenggunakanaspal keras (ACPen60/70).

3. Bahan pengisi FillermenggunakanSemen portland.

\section{Hasil dan Pembahasan}

\subsection{Hasil Pengujian}

a. Hasil Pengujian Agregat

Hasil pengujian agregat disajikan dalam Tabel 4.1 
Tabel 4.1. Hasil Pengujian Agregat

\begin{tabular}{lccc}
\hline \multicolumn{1}{c}{ Pengujian } & $\begin{array}{c}\text { Batu split long } \\
\text { ikis agrega } \\
\text { kasar }\end{array}$ & $\begin{array}{c}\text { Batu split long } \\
\text { ikis agrega } \\
\text { halus }\end{array}$ & $\begin{array}{c}\text { Spesifikasi } \\
\text { Bina Marga } \\
2010\end{array}$ \\
\hline Abrasi & \multicolumn{2}{c}{$21,12 \%$} & Maks.40\% \\
\hline Berat Jenis: Berat jenisbulk & $2,60 \%$ & $2,57 \%$ & Min. 2,5\% \\
\hline SSD & $2,63 \%$ & $2,62 \%$ & Min. 2,5\% \\
\hline Berat Jenis Semu & $2,68 \%$ & $2,72 \%$ & Min. 2,5\% \\
\hline Penyerapan & $1,07 \%$ & $2,14 \%$ & Maks. 3\% \\
\hline
\end{tabular}

Tabel 4.2 Hasil Pengujian Marshall

$\begin{array}{cc}\text { Spesifikasi } & \text { KadarAsp } \\ \text { Karakteristik } & \text { al(\%) }\end{array}$

\begin{tabular}{lccccccc}
\hline & $\mathbf{2 0 1 0}$ & $\mathbf{4 , 5}$ & $\mathbf{5 , 0}$ & $\mathbf{5 , 5}$ & $\mathbf{6 , 0}$ & $\mathbf{6 , 5}$ & $\mathbf{7 , 0}$ \\
\hline Stabilitas(kg) & $\mathbf{2 8 0 0}$ & 1223 & 1378 & 1317 & 1396 & 1256 & 1299 \\
\hline Flow $(\mathbf{m m})$ & $\mathbf{3}$ & 2,03 & 2,07 & 3,01 & 3,20 & 3,73 & 4,53 \\
\hline VMA (\%) & $\geq \mathbf{1 5}$ & 16,9 & 15,8 & 16,4 & 16,8 & 17,6 & 16,1 \\
\hline VIM (\%) & $\mathbf{3 , 5 - 5 , 5}$ & 7,5 & 5,0 & 4,5 & 3,7 & 3,5 & 1,7 \\
\hline VFA(\%) & $\mathbf{2 6 5}$ & 55,9 & 68,2 & 72,5 & 77,6 & 80,2 & 89,6 \\
\hline $\begin{array}{l}\text { Marshal } \boldsymbol{Q} \\
(\mathbf{k g} / \mathbf{m m})\end{array}$ & $\geq \mathbf{2 5 0}$ & 601 & $\mathbf{6 6 5}$ & 438 & 436 & 337 & 288 \\
\hline
\end{tabular}

Hasil pengujian keausan agregat dari Long Ikis dengan mesin Abrasi Los Angeles didapatkan nilai sebesar 21,12 \%, maka agregat tersebut memenuhi persyaratan. Syarat keausan agregat maksimum 40\%, (Binamarga 2010).

Dari pengujian berat jenis dan penyerapan agregat batu split Long ikis didapat berat jenis sebesar 2,60 dan penyerapan didapat 1.07. Maka dari pengujian tersebut masih memenuhi syarat untuk berat jenis > 2,5 dan penyerapan < 3. (Bina Marga 2010).

\section{b. Hasil Pengujian Marshall}

Pengujian Marshall pertama dilakukan terhadap 18 buah benda uji dengan 6 variasi kadar aspal $(4,5 \% ; 5,0 \% ; 5,5 \% ; 6,0 \% ; 6,5 \%$, $7,0 \%$ ), yang bertujuan untuk mengetahui nilai-nilai karakteristik Marshall dari campuran aspal tersebut. Hasil pengujian Marshall terhadap campuran beton aspal ACWC dapatdilihat dalam Tabel 4.2.

\subsection{Pembahasan}

\section{a. Material Campuran Beton Aspal}

Berdasarkan dari hasil pengujian 
laboratorium yang tertera pada Tabel 4.1, menunjukkanbahwa material agregat yang diperoleh dari hasil produksi mesin pemecah batu Split Long Ikis tersebut memenuhi standar yang disyaratkan Spesifikasi Umum Bina Marga 2010, sehingga dapat digunakan sebagai agregat pada campuran AC-WC.

\section{b. Hasil Pengujian Marshall pada Kadar Aspal Optimum}

Pengujian ini dimaksudkan untuk mengetahui kehilangan stabilitas setelah rendaman yang dinilai sebagai kerusakan akibat pengaruh air dan kemampuan campuran perkerasan aspal untuk menahan kerusakan yang diakibatkan oleh perubahan beban.

Setelah kadar aspal optimum diperoleh, benda uji dibuat pada $6,0 \%$, kemudian dilakukan perendaman 30 menit dan 24 jam pada suhu $60^{\circ} \mathrm{C}$ dengan masing masing tiga jumlah benda uji.Tabel 4.3 Hasil Marshall test pada kadar aspal optimum $6,0 \%$.

Tabel 4.3 Hasil Penentuan Karakteristik Marshall Test

\begin{tabular}{|c|c|c|c|c|c|c|c|c|c|}
\hline \multirow[b]{2}{*}{$\begin{array}{l}\mathbf{N} \\
\mathbf{O}\end{array}$} & \multirow[b]{2}{*}{$\begin{array}{c}\text { Karakteristi } \\
\text { k Marshall } \\
\text { Test }\end{array}$} & \multicolumn{4}{|c|}{ Perendaman 30 menit } & \multicolumn{4}{|c|}{ Perendaman 24 jam } \\
\hline & & 1 & 2 & 3 & $\begin{array}{c}\text { Rata } \\
\text { - rata } \\
\end{array}$ & 1 & 2 & 3 & $\begin{array}{c}\text { Rata } \\
- \\
\text { rata } \\
\end{array}$ \\
\hline 1 & $\begin{array}{l}\text { Stabilitas } \\
(\mathrm{kg})\end{array}$ & $\begin{array}{c}1.30 \\
0\end{array}$ & $\begin{array}{c}1.35 \\
1\end{array}$ & 1.326 & 1.326 & 1.606 & 1.530 & 1.299 & 1.478 \\
\hline 2 & $\begin{array}{l}\text { Pelelehan } \\
(\mathrm{mm})\end{array}$ & 3,20 & 2,75 & 3,34 & 3,10 & 3,68 & 3,93 & 3,49 & 3,70 \\
\hline 3 & $\begin{array}{l}\text { Hasil Bagi } \\
\text { Marshall } \\
(\mathrm{kg} / \mathrm{mm})\end{array}$ & 406 & 491 & 397 & 431 & 436 & 389 & 372 & 399 \\
\hline 4 & VIM (\%) & 5,7 & 5,4 & 5,5 & 5,5 & 5,37 & 5,42 & 2,63 & 4,5 \\
\hline 5 & VMA (\%) & 17,4 & 17,2 & 17,3 & 17,3 & 17,18 & 20,30 & 14,78 & 17,4 \\
\hline 6 & VFA $(\%)$ & 67,6 & 68,7 & 68,0 & 68,1 & 68,8 & 73,3 & 82,2 & 74,8 \\
\hline
\end{tabular}

\section{Stabilitas Marshall}

tabilitas marshall test dengan menggunakan material Batu Split Long Ikis pada perendaman 30 Menit adalah $1394 \mathrm{Kg}$ dan pada perendaman 24 Jam dengan nilai $1317 \mathrm{~kg} \geq 800 \mathrm{~kg}$ sesuai spesifikasi AC-WC.

\section{Flow atau Pelelehan}

Campuran beraspal panas dengan nilai flow pada perendaman 30 Menit adalah 3,43mm dan pada perendaman 24 Jam dengan nilai $3,20 \mathrm{~mm} \geq 3 \mathrm{~mm}$ sesuai spesifikasi AC-WC.

\section{VMA}

Pada perendaman 30 menit diperoleh nilai VMA yaitu $17,1 \%$ sesuai pada spesifikasi AC-WC dan pada perendaman 24 jam dengan nilai 17.0 $\%$ sesuai pada nilai VMA yaitu $\geq 15 \%$.

\section{VIM}

VIM pada perendaman 30 menit dan 24 jam dengan nilai 5,3\% dan 4,0 sesuai pada spesifikasi AC-WC adalah $3,5 \%-5,5 \%$.

\section{VFA}

Dengan menggunakan material batu split Long Ikis pada perendaman 30 menit dan 24 jam dengan nilai $69,1 \%$ 
dan 77,1 sesuai pada spesifikasi ACWC bahwa syarat VFA $>65,0 \%$.

\section{Marshall Quotiet}

MQ dengan menggunakan batu split Long Ikis pada perendaman 30 menit adalah $409 \mathrm{~kg} / \mathrm{mm}$ dan pada perendaman 24 jam dengan nilai 421 $\mathrm{kg} / \mathrm{mm}$ sesuai pada spesifikasi AC$\mathrm{WC}$ adalah $\geq 250,0 \mathrm{~kg} / \mathrm{mm}$.

\section{Kesimpulan}

\section{Kesimpulan}

1. Persentase hasil pengujian agregat menunjukkan nilai yg memenuhi spesifikasi dengan hasil uji abrasi 21,12\%<40\%, berat jenis > 2,5\% dan penyerapan $<3$ sehingga dapat digunakan sebagai material perkerasan jalan.

2. Parameter Marshall pada kadar aspal rencana $(\mathrm{Pb})$ untuk sifat stabilitas, flow, MQ dari ketiga kelompok benda uji nilai yang di dapat hanya nilai flow sebagian yang tidak memenuhi syarat Spesifikasi sedangkan nilai stabilitas dan MQ sudah memenuhi spesifikasi.

Hasil pengujian Parameter Marshall pada kadar aspal rencana $(\mathrm{Pb})$ didapat nilai Kadar Aspal Optimum (KAO) 5,83\% dibulatkan 6,0\%. Untuk hasil Parameter Marshall perendaman 30 menit dan perendaman 24 jam pada suhu $60^{\circ} \mathrm{C}$ didapat nilai stabilitas $1326 \mathrm{~kg}$ dan $1478 \mathrm{~kg}$, flow $3,10 \mathrm{~mm}$ dan $3,70 \mathrm{~mm}$, VMA $17,3 \%$ dan $17,4 \%$, VIM $5,5 \%$ dan $4,5 \%$, VFA $68,1 \%$ dan
$74,8 \%$ dan MQ $431 \mathrm{~kg} / \mathrm{mm}$ dan $399 \mathrm{~kg} / \mathrm{mm}$. telah memenuhi syarat spesifikasi.

\section{Daftar Pustaka}

1. Anonim, 1991, Metode Pengujian Campuran Aspal Dengan Alat Marshall, SNI 062489-1991, Jakarta

2. Anonim, 2008, Metode Cara Uji Keausan Dengan Mesin Abrasi Los Angeles, SNI 2417-2008, Jakarta

3. Anonim, 2008, Cara Uji Berat Jenis dan Penyerapan Air Agregat Halus, SNI 1970-2008, Jakarta

4. Anonim, 2002, Cara Uji Berat Jenis dan Penyerapan Air Agregat Halus, SNI 03-68192002, Jakarta

5. Anonim, 2010, Bab VII Devisi 6 Perkerasan Aspal. Departemen Pekerjaan Umum, Jakarta

6. Buku Petunjuk Umum, Manual Pekerjaan Campuran Beraspal Panas, Dinas Pekerjaan Umum, Bina Marga 2010.

7. Bodja Suwanto et.al., 2002 , Perkerasan Lentur Jalan Raya.

8. Marsudi, 2004, Kontruksi Perkerasan Jalan.

9. Marthin H. Tambunan, "Pengaruh Pasir Alam Binjai Terhadap Sifat Campuran ACWC", Tugas Akhir S1, Teknik Sipil USU, 2010.

10. Sukirman, Silvia (2003) Perkerasan Jalan. Bandung : Nova 